\title{
20q11.2 microduplication syndrome
}

INSERM

\section{Source}

INSERM. (1999). Orphanet: an online rare disease and orphan drug data base. 20911.2 microduplication syndrome. ORPHA:363659

$20 q 11.2$ microduplication syndrome is a rare chromosomal anomaly syndrome, due to partial duplication of the long arm of chromosome 20, characterized by psychomotor and developmental delay, moderate intellectual disability, metopic ridging/trigonocephaly, short hands and/or feet and distinctive facial features (epicanthus, hypoplastic supraorbital ridges, horizontal/downslanting palpebral fissures, small nose with depressed nasal bridge and anteverted nostrils, prominent cheeks, retrognathia and small, thick ears). Growth delay and cryptororchidism are often associated features. 